\title{
A Study on the Causes and Solutions of College English Teachers’ Job Burnout
}

\author{
ZHANG Yan-qiu, FENG Bin \\ Changchun University, Changchun, China
}

\begin{abstract}
With the continuous deepening of foreign language teaching reform and the dramatic changes of social and institutional environment, the requirements for college English teachers are constantly improved. College English teachers suffer a strong sense of anxiety and burnout. The job burnout of college English teachers not only affects the professionalization of teachers, but also affects their physical and mental health. In addition, the state of college English teachers will also affect the quality and future development of college English teaching. This paper enumerates the typical manifestations of college English teachers' job burnout, explores its causes, and tries to adopt effective countermeasures and methods to alleviate and intervene the job burnout of college English teachers. It is believed that this study is of positive and practical significance for English teachers to get out of trouble, and further improve the quality of foreign language teaching and comprehensively deepen the reform of foreign language teaching.
\end{abstract}

Keywords: job burnout, college English teachers, causes of job burnout, countermeasures of job burnout, coping strategies

\section{Introduction}

American foundation clinical psychology specialist Freudenberger (1974) first brought the concept of job burnout into psychology research. He defines burnout as an exhausted mental and physiological state, which results from long-term work pressure. One loses his/her enthusiasm for work because he/she cannot get alleviated effectively, so his/her working performance is affected correspondingly. Maslach and Jackson (1986) pointed out emotional exhaustion, depersonalization, a sense of reduced personal accomplishment, chronic fatigue, depletion of feelings, and a desire to withdraw were symptoms of burnout. They conclude that burnout is a loss of idealism and enthusiasm about a job or a role and is a gradual process of disillusionment. Their definition of burnout and the measures confirming burnout are widely accepted.

The syndrome of job burnout includes irritability, frustration, exhaustion, cynicism, inefficiency, emotional instability, decreased sense of self-esteem, physical and mental problems, and so on. As a high risk group of job burnout, college English teachers have become the focus of research on job burnout in China.

With rapid social and economic development, the requirements for college English teachers have been improved continuously. Facing the change of macro and micro environment, college English teachers are confused and powerless about their professional development and anxious and tired about their career, which

ZHANG Yan-qiu, master, associate professor, School of Foreign Languages, Changchun University, Changchun, China. FENG Bin, master, associate professor, School of Foreign Languages, Changchun University, Changchun, China. 
has become a serious problem. Teachers' job burnout has become one of the most important factors affecting teacher professionalism and even the physical and mental health of individual teachers. At the same time, as the practitioner of education, the professional degree of college teachers also affects the quality of education. It is of great practical significance to explore the causes of college English teachers' job burnout and to take effective countermeasures to ease college English teachers' job burnout.

\section{Factors Lead to College English Teachers’ Job Burnout}

According to this study, we find that the causes of college English teachers' job burnout can be classified into three categories: individual factors, institutional factors, and social factors.

\section{Individual Factors}

College English teachers have a lot of pressure. As is known to all, positional titles are of great importance for college English teachers. It is closely related to the social status, career development, and income of college English teachers. Inferior positional titles are not preferred by judges of advanced research projects and editors of well-known journals. In fact, positional titles are so-called an effective label for a teacher's ability and achievement. However, the competition for positional titles has been very fierce due to the limited quotas. How many advanced research projects you hold and how many papers you publish in famous journals is the main criterion for positional titles. To apply advanced projects successfully and publish papers in famous journals become the key task for college English teachers. This task requires high academic ability and the number is comparatively small with the large number of applicants. Besides talents, disciplines of Humanities and Social Science require long-term accumulation. In other words, without lots of input, the high quality output is impossible. Therefore, lots of work should be done for applying for positional titles. Reading books and journals and trying to write research project applications and papers is daily routine for most college English teachers. Besides, another job makes academic research more challenging than positional titles. That is, in some well-known universities, if newcomers cannot finish the required research task and get a title of associate professor within certain period of time, he or she should resign. For old teachers, there are also different research tasks to finish within certain period of time corresponding to different positional titles. Punishment will follow if the task is not completed on time.

The second primary source of pressure comes from teaching. As a language teacher, you should possess high competence for language use to serve as a model for students. Therefore, college English teachers need to constantly improve their listening, speaking, reading, and writing ability. Second, teachers need to put more time and energy in preparing for classes. Students' linguistic level is much more improved compared with students several years ago. And with rich resources of language study on the Internet, teachers should display their own distinctive characteristics and play an irreplaceable role in students' language learning. Moreover, various language teaching reforms take place and language teachers need to alter their teaching concepts and behaviors in order to conform to the spirits of the reform. Finally, the new academic evaluation system makes teachers tired to cope with various challenges. How can they avoid burnout in such a stressful external atmosphere?

The third primary source comes from the improvement of academic degrees. In today's society, having a doctoral degree seems a prerequisite for a teaching post in universities. Therefore, for college English teachers with a mater degree, getting a doctoral degree is necessary. However, the competition to apply for a doctoral 
degree of English language is extremely fierce because the number of universities with doctoral degrees of English language is smaller than other disciplines. Even you are excellent enough to become a doctor candidate, it is also difficult to graduate. College English teachers who are also doctor candidates are very anxious, even upset because to graduate and get a doctoral degree successfully is also a challenging task.

\section{Institutional Factors}

Another factor that leads to college English teachers' job burnout is the operational way of college. Administerization and bureaucracy are the two obvious characteristics. Administerization means that at college leaders of administrative management departments and their staff is the dominant body and determines the rules and principles of its operation. They emphasize their authority and power, and they do not have the concept of serving teachers. Teachers do not possess the autonomy and power of speech and they are the objects of management. Bureaucracy is also obvious at college. Administrative management departments do not know teaching and rules of academic research, but they design rules and regulations of teaching and research without listening to the voice of teachers. Therefore, the phenomenon that laymen lead experts happens often. The reality at college is that teachers are burdened with lots of meaningless work and restricted by lots of rules and regulations. Teachers have little space to be creative and display their own distinctive character in teaching. They are struggling to cope with the scientific research tasks every year. The gap between teachers and administrative leaders and staff leads to the bugs of college operations and cause the job burnout of English teachers.

College English teachers are engaged in intensive teaching activities and scientific research activities, which undoubtedly requires huge physical and mental resources. The excessive work load leads to the excessive consumption of psychological energy, as a result, emotional exhaustion and job burnout comes out. In addition, the significance of their efforts can only be shown after a long time, and the delay of such selfrealization will damage the sense of self-achievement of college English teachers.

\section{Social Factors}

There are high requirements and expectations for college English teachers: Being selfless, positive, responsible, enthusiastic, energetic, etc., they should sacrifice their personal interests for work and be a model of virtue for others, thus restraining and denying the desire as normal people. They have to pay attention to their own image at any time and any place, which often leads to pressure.

With the rapid development of market economy, power, and money has become a new standard to measure social status and social value for the public. The diversity of value system brings new challenges to teachers. The impassable gap between the dream and reality makes teachers gradually feel inferior and embarrassed. The psychological conflicts and self-doubt are always haunting around them. Their income is comparatively low and cannot support the family well. The economic burden often brings anxiety to college English teachers.

\section{Counter Measures to College English Teachers' Job Burnout}

\section{For Individual Factors}

For academic research, colleges should set up a flexible system which permits teachers enough time to accumulate. Colleges should follow the law of disciplines of Humanities and Social Science that only sufficient input can ensure sufficient output. The evaluation for teachers should also be fair and reasonable. A long-term 
assessment should be advocated instead of too frequent and harsh ones. Teachers' professional development is a long-term process, which cannot be accomplished overnight. A scientific teacher evaluation system is both beneficial to teachers themselves and their career development.

At the same time, colleges should desert the prejudice against the liberal arts language, especially linguistics through increasing the quota of positional titles to college English teachers. For applying for research projects, teachers with inferior positional titles should not be discriminated against and should be offered equal opportunities as the superior ones. Moreover, applying for an interdisciplinary doctoral degree should be encouraged.

For teaching, colleges should respect teachers' creativity and personality, avoiding to "block" the classes. Teachers should be accessible to more professional training and academic conferences to get new information about teaching. Colleges should evaluate teachers' performance objectively and provide as much guidance and help as possible for teachers' professional development.

In addition, foreign language teaching and learning should obey certain rules and laws, thus reforms should be based on scientific research and teaching reality. Reforms for reforms' sake should not be advocated. Finally, reduce unnecessary assessments of teachers to help teachers save time and energy. Under lots of pressure, teachers cannot explore their own potential and more space and freedom is called for to teaching.

\section{For Institutional Factors}

Colleges should center on de-administration, enhance service awareness, and respect teachers' autonomy and speech rights. The administrative management departments and their staff should clarify the purposes of their job, providing services to teachers instead of putting themselves above teachers. Teachers' equal participation and joint decision in various affairs of colleges and universities should be assured.

To improve the level and efficiency of democratic management, it is necessary to build normal and efficient democratic management system. Discussion and consultation mechanism should be improved, too. For example, establish open communication channels, such as regular meetings, network discussion, special letterbox, and the principal's reception day for information exchange, so that teachers can fully understand the intention behind the rules and regulations issued by colleges.

\section{For Social Factors}

College English teachers are also social beings. Their social identity comes before their identity of teachers. Being in a good state as a teacher should be, first of all, in a good state of a social being. Society should improve the social status and economic benefits of college English teachers, and help them solve the practical difficulties. At the same time, society should increase the fund invested in higher education, while improve college English teachers' living and working conditions. In addition, more efforts should be made to create a good working environment for teachers and provide the care and guidance for teachers' mental health. The country should make supporting policies and laws to protect the independent rights and interests of teachers.

Teacher's job burnout is a kind of psychological symptoms, and it is necessary to relieve it through psychological intervention. The psychological health care system should be established, such as setting up individual psychological consultation institutions, opening a hotline and setting up a mailbox for teachers' psychological consultation. 
In addition, mental health education can be introduced into the in-service education of teachers. Independent mental health courses can help guide teachers to understand psychological phenomena, such as negative emotions, pressure, and frustration, and learn self-management and self-adjustment methods. Psychological activities, such as group counseling and outdoor quality training among teachers can help relieve teachers' job burnout in early period.

\section{Conclusion}

College English teachers are not only knowledge communicators, but also researchers, organizers, integrators of resources, psychological counselors, students' friends, and so on. It is very difficult for college English teachers to play so many roles. Therefore, the negative emotions, such as confusion, dissatisfaction, and pressure can easily come into being and accumulate over time to form job burnout. On the other hand, lifelong learning is the theme of the era, which is especially true for teachers. In the process of teachers' growth from a beginner to an expert and from immaturity to maturity, job burnout always accompanies, which will inevitably affect or even restrict the professional development of teachers.

At present, China is in the period of social reform and development, where the main trend is the respect to knowledge and talents. An atmosphere of respecting teachers and attaching importance to education is formed in the whole society. Teachers should be properly respected by the society, and they should develop a sense of professional identity and a sense of pride and belonging. The role and social status of teachers are scientifically and objectively positioned in accordance with the social expectations and teachers' self-expectations. Only in this way, can teachers carry out their teaching and research in a relaxed and pleasant environment.

\section{Acknowledgement}

This paper is the research results of the planning projects of 2018 Jilin Province Educational Department Thirteenth Five-Year social sciences research "Research on the Factors and Solutions of College English Teachers’ Job Burnout” (Project Number: 2018LY503W10); 2017 Jilin Science Education Thirteenth Five-Year Plan "Research on the Application of PBL in College English Courses for Students with Hearing Impairment " (Project Number: GH170134); 2017 Changchun University research project "Research on the Mixed Teaching Model of College English Based on Spoc in Application-oriented Universities" (Project Number: XJZD17-13).

\section{References}

Cephe, P. T. (2010). A study of the factors leading English teachers to burnout. Hacettepe University Journal of Education, (38), 25-34.

Freudenberger, H. J. (1974). Staff burnout. Journal of Social Issues, (1), 159-164.

Malikow, M. (2007). Staying motivated and avoiding burnout. Kappa Delta, Pi Record, 43(3), 117-121.

Maslach, C. (2003). Job burnout: New directions in research and intervention. Current Directions in Psychological Science, 12(5), 89-192.

Maslach, C., \& Jackson, S. (1981). The measurement of experienced burnout. Journal of Occupational Behavior, 2(2), 99-113.

Maslach, C., \& Jackson, S. (1986). The Maslach burnout inventory. Palo Alto, Calif: Consulting Psychologists Press. 